\title{
Visita Domiciliar e Saúde Mental: um relato de experiência
}

\author{
Home visit and mental health: \\ an experience report
}

\section{Catharine Marcella Rosas de Araújo' ${ }^{1}$ (i) Jéssica Plácido Silva² ${ }^{2}$}

\begin{abstract}
1Escola Bahiana de Medicina e Saúde Pública (Salvador). Bahia, Brasil. psicatharinerosas@outlook.com ${ }^{2}$ Autora para correspondência. Escola Bahiana de Medicina e Saúde Pública (Salvador), Universidade Federal da Bahia (Salvador). Bahia, Brasil.
\end{abstract} jelplacido@hotmail.com

RESUMO | INTRODUÇÃO: As atividades práticas durante a graduação são oportunidades para os estudantes lidarem com sujeitos reais. Quando tais atividades ocorrem no âmbito do Sistema Único de Saúde, principalmente, na atenção primária, é oferecido ao estudante a noção de pluralismo sociocultural. OBJETIVO: Discutir a importância das Visitas Domiciliares enquanto atividade docente-assistencial, identificando os benefícios, as potencialidades e os desafios dessa ferramenta. METODOLOGIA: Trata-se de um relato de experiência sobre a prática das Visitas Domiciliares num contexto pedagógico, em um Internato de Psicologia. RESULTADOS E DISCUSSÕES: O internato em atenção primária à saúde acontece no Complexo Comunitário Vida Plena, localizado em Pau da Lima, bairro periférico de Salvador. Nessa unidade de saúde, o protocolo para visita domiciliar consiste em Planejamento, Visita, Supervisão e Confecção do relatório. O planejamento é realizado através da leitura do prontuário. Tal leitura proporciona o contato prévio com a família e a possibilita a confecção de objetivos específicos para visita. Durante a visita, é necessário lidar com o tempo emocional e cronológico, vínculo sem julgamento, escuta atenta, interferência dos familiares e vizinhos, vulnerabilidade e risco social, educação em saúde e, sobretudo, questões psicológicas dos usuários. A supervisão, compreendida como um momento de facilitação e suporte aos estudantes, desenvolveu nossa criticidade e amadureceu a correlação teoria-prática. Na confecção do relatório, as palavras registradas precisavam ser escolhidas com esmero para garantir o acompanhamento de qualidade dos usuários. CONCLUSÃO: As Visitas Domiciliares são instrumentos potentes de formação. Viver a experiência com autonomia e ao mesmo tempo tendo a orientação e o apoio da professora, foi o grande diferencial.

PALAVRAS-CHAVE: Assistência domiciliar. Formação profissional. Psicologia. Saúde mental.
ABSTRACT | INTRODUCTION: Pratical activities during graduation are opportunities for students to deal with real subjects. When such activities occur within the scope of the Unified Health System, especially in primary care, the student is offered the notion of sociocultural pluralism. OBJECTIVE: Discuss the importance of Home Visits as a teaching-assistance activity, identifying the benefits, potential and challenges of this tool. METHODOLOGY: This is an experience report about the pratice of Home Visits in a pedagogical context, in a Psychology Internship. RESULTS AND DISCUSSIONS: The boarding school in pimary health care happens in the Complexo Comunitário Vida Plena, located in Pau da Lima, a peripheral neighborhood of Salvador. In this health unit, the protocol for home visits is based on the following steps: Planning, Visiting, Supervising and Writing the Report. Planning is carried out by Reading the medical record. This reading, providing prior contact with the Family and enable to set specific goals for the visit. During the visit, it was necessary to deal with emotional and chronological time, bond without judgment, attentive listening, interface from family and neighbors, vulnerability and social risk, health education and, above all, psychological issues of users. Supervision was understood as a moment of facilitation and support us, having been developed our criticality and matured the theory-pratice correlation. In the preparation of report, the registered words had to be carefully chosen, to ensure quality monitoring of users. CONCLUSION: Home Visits are powerful training tools. Living the experience with autonomy and at the same time, having the guidance and support or out teacher, was the great differential.

KEYWORDS: House calls. Professional training. Psychology. Mental health. 


\section{Introdução}

Desde os primeiros semestres do curso, os estudantes de Psicologia, geralmente, anseiam pelo início das atividades práticas, para que assim possam desenvolver as habilidades psicológicas, outrora aprendidas. As Diretrizes Curriculares Nacionais dos Cursos de Graduação em Psicologia (2019) preconizam que $20 \%$ da carga horária total do curso deve ser dedicada aos estágios obrigatórios de núcleo comum e estágios de ênfases curriculares. Os estágios de núcleo comum são aqueles que "incluem o desenvolvimento e a integração das competências previstas no núcleo comum da formação e devem contemplar a diversidade do campo da Psicologia" (DCN, 2019, p. 12). Já os estágios de ênfase, "visam ao desenvolvimento e à integração das competências ligadas aos diferentes processos de trabalho desenvolvidos nas ênfases curriculares do curso e ao perfil de cada instituição formadora" (DCN, 2019, p. 12).

Na Instituição de Ensino Superior em que a experiência foi realizada, existe uma modalidade de estágio de núcleo comum chamado "internato". Nesta Instituição, depois de três anos obtendo todo aparato teórico necessário, o internato surge como oportunidade de iniciar a experiência do "ser psicóloga"; e um marco significativo para essa mudança, é a oportunidade de interromper com sujeitos hipotéticos (que por muito tempo nos serviram), para agora lidar com os sujeitos concretos. Esses sujeitos são biopsicossociais e têm histórias de vida que pertencem a um mundo real. No entanto, por ser um momento de crescimento profissional e pessoal em que o estudante precisa reconhecer suas limitações e trabaIhar suas habilidades interpessoais, essa experiência pode se tornar bastante desafiadora (Gama \& Koda, 2008; Pitombeira et al., 2016).

Segundo Sirgado (1990), através do trabalho, o homem relaciona-se com a natureza; sendo ao mesmo tempo agente transformador e transformado por ela (apud Santos \& Nóbrega, 2017). Nesse sentido, consideramos que as atividades práticas, quando desenvolvidas em espaços públicos, no âmbito do Sistema Único de Saúde (SUS) e, principalmente, na atenção primária à saúde, oferecem ao estudante a oportunidade de se relacionar com tal natureza e de compreender o pluralismo sociocultural em que está inserido (Pitombeira et al., 2016). Essa abordagem afetará sua forma de interagir com as pessoas e propiciará a ampliação do fazer do psicólogo (Gama \& Koda, 2008).

Isto posto, uma das inúmeras atividades oferecidas pelo Sistema Único de Saúde, através da atenção primária, são as Visitas Domiciliares (VD), que possuem o potencial de proporcionar o deslocamento do estudante. Por envolver falas, escutas, observações e interpretações, a VD promove a intersubjetividade (Cunha \& Sá, 2013). Ademais, nas visitas domiciliares, o aluno aprende a se comunicar com pessoas desconhecidas e ao mesmo tempo é capaz de proporcioná-las conhecimento sobre as temáticas que dizem respeito aos seus problemas de saúde (Romanholi \& Cyrino, 2012).

As visitas domiciliares podem ser caracterizadas como ferramentas que permitem o cuidado à saúde de forma humanitária, acolhedora e capaz de estabelecer laços de confiança entre os profissionais, a família e a comunidade. Além de possibilitar o acesso, de forma ampliada, das populações a ações de saúde, em um dos pontos de sua rede de atenção, podendo ser o próprio domicílio ou a unidade de saúde. (Andrade, Guimarães, Costa, Machado, \& Gois, 2014)

A Estratégia de Saúde da Família (ESF) fez das visitas domiciliares parte integrante das atividades que são atribuídas à equipe de saúde. Essa atividade torna a ESF ainda mais preciosa, pois, a VD é um expressivo diferencial na prestação de cuidado em saúde no Brasil. (Sakata, Almeida, Alvarenga, Craco e Pereira, 2007)

A VD é considerada tecnologia leve, produtora de comunicações dialógicas e que favorece a integralidade do cuidado. As VDs, em decorrência da profunda inserção nos lares e a relação com o elo intrafamiliar, são ricas oportunidades de compreensão dos modos de vida dos indivíduos. Nesse contexto, é possível abordar questões de ordem emocional, não se atendo apenas às doenças físicas. (Sakata et al., 2007). No entanto, as VDs implicam alguns desafios particulares à sua pratica, como: a dificuldade de lidar com uma demanda que não é diagnosticada e por isso possui necessidades desconhecidas, vivenciar o contato direto com o imprevisível, adentrar na casa das pessoas e suas intimidades e prescrever estilos de vida (Cunha \& Sá, 2013). 
Todos esses benefícios e desafios são potencializados quando a VD é voltada para famílias que possuem alguma pessoa com transtorno mental. Nesses casos, a função da equipe de saúde pode envolver o acolhimento do usuário e de toda a família, o diagnóstico e orientação sobre o transtorno, a construção de estratégias para inserção social do usuário e outras ações. Esse modelo de atendimento supera o modelo hospitalocêntrico, pois através de uma equipe interdisciplinar, envolve a família, a comunidade e o os equipamentos urbanos disponíveis no território. (Silva, Teixeira, Sabóia, \& Cavalcanti Valente, 2011).

Essa modalidade de atendimento às pessoas com transtornos mentais só foi possível depois da Reforma Psiquiátrica Brasileira, produto de um longo período de debates coletivos e construção de leis e portarias, concentrado no período de 1989 a 2003. Anteriormente a assistência à saúde mental era centrada nos hospitais especializados, chamados manicômios, espaços que excluíam as pessoas em condições de saúde mental da vida em comunidade. A Reforma Psiquiátrica redireciona a forma de cuidado na assistência psiquiátrica, apresentando ações até então desconhecidas e que preveem a inclusão dos indivíduos na sociedade e na cultura, preparando-os para a dinâmica do cotidiano, bem como, orientando a família e a sociedade em geral para essa inclusão. (Berlinck et al., 2008)

Uma das principais regulamentações para concretização da Reforma Psiquiátrica surgiu em 2002, quando o Ministério da Saúde estabeleceu através da Portaria 366 o funcionamento dos Centros de Atenção Psicossocial (CAPS) como principal estratégia para cuidado das pessoas com transtornos mentais. Segundo a portaria, os CAPS podem se configurar enquanto CAPS I, CAPS II ou CAPS III, de acordo com a quantidade populacional. O CAPS I e CAPS ॥ funcionam das $08 \mathrm{~h}$ às $18 \mathrm{~h}$ nos 05 dias úteis da semana e incluem em sua assistência atendimento individual e em grupo, oficinas terapêuticas, visitas domiciliares, atendimento à família e atividades comunitárias; diferenciando-se apenas ao que se refere ao número de habitantes do município, sendo o CAPS I para municípios entre 20 mil e 70 mil moradores e o CAPS II, 70 mil a 200 mil. Já o CAPS III tem uma capacidade de funcionamento para municípios com número de habitantes superior a 200 mil e caracteriza-se por oferecer "um serviço ambulatorial de atenção contínua, durante 24 horas diariamente, incluindo feriados e finais de semana" (artigo 4), além de incluir todas as atividades dos CAPS I e CAPS II (Ministério da Saúde, 2002).

Alguns anos depois, em 2011, o Ministério da Saúde decide ampliar o suporte às pessoas com necessidades em saúde mental e cria a Rede de Atenção Psicossocial (RAPS), através da Portaria 3088. Essa portaria muda a perspectiva de cuidado dos usuários na medida em que expande para além do Centro de Atenção Psicossocial a assistência às pessoas em sofrimento ou transtorno mental e integra diversos equipamentos de saúde como a própria Unidade Básica de Saúde, os serviços de Pronto Atendimento, os serviço de Atendimento Móvel de Urgência, Hospitais, etc. Com o funcionamento preciso da RAPS as pessoas tem acesso a um conjunto de estratégias que objetivam a manutenção da sua autonomia, a garantia dos direitos humanos e a atenção humanizada centrado em suas necessidades, além de gerar ações compatíveis com o território e coerentes com a comunidade, agregando maior participação e controle dos atendidos e seus familiares. Esses últimos pontos são mais facilmente garantidos por meio da atuação da UBS, já que essa ocupa um papel estratégico na aplicação da RAPS. Assim sendo, a VD realizada pela UBS com foco na saúde mental é uma tecnologia que permite a educação permanente, o acompanhamento contínuo, a qualidade do cuidado por meio do acolhimento e, por isso, auxilia no cumprimento da RAPS em geral.

Diante da complexidade das visitas domiciliares e todas as oportunidades de desenvolvimento profissional e pessoal que essa atividade é capaz proporcionar, sentimos necessidade de compartilhar as experiências de internato rotatório de uma estudante de Psicologia da cidade do Salvador, Bahia. Portanto, o presente trabalho tem como objetivo discutir a importância das Visitas Domiciliares, enquanto atividade docente-assistencial, identificando os benefícios, as potencialidades e os desafios dessa ferramenta. 
Método

Internato rotatório é uma atividade pedagógica de ensino superior do curso de Psicologia, da Escola Bahiana de Medicina e Saúde Pública, localizada em Salvador, Bahia. Esse formato de estágio do núcleo comum, denominado pela Instituição de "internato", é dividido em quatro rodízios/quatro áreas de atuação em Psicologia: atenção primária à saúde, atenção secundária, atenção terciária e Psicologia organizacional e do trabalho. Todos os rodízios duram 10 semanas, somando um total de 120 horas práticas e contam com a orientação direta de uma professora de Psicologia da Instituição; a professora deve ser especialista naquele campo de atuação. Em cada rodízio há, no máximo, 10 estudantes. $O$ internato em Psicologia acontece no quarto e penúltimo ano da graduação ( $7^{\circ}$ e $8^{\circ}$ semestres), antes dos estágios obrigatórios supervisionados de ênfase curricular. A experiência aqui relatada ocorreu entre os meses de janeiro a abril, do ano de 2018.

O internato em atenção primária à saúde, desde o seu início em 2012.1, acontece no Complexo Comunitário Vida Plena (CCVP). O CCVP é uma Unidade de Saúde localizada no bairro de Pau da Lima, um bairro periférico de Salvador. As atividades desse rodízio versam sobre: acolhimento humanizado, formação e desenvolvimento de grupos, atividades de territorialização e realização das visitas domiciliares. Todas as atividades do internato visam o desenvolvimento profissional através da introdução dos estudantes na realidade cotidiana da população de Salvador. Dentre as tarefas realizadas, iremos aprofundar neste artigo o aspecto pedagógico das Visitas Domiciliaress. As VDs realizadas pelo grupo do internato faziam parte da Linha de Cuidado em Saúde Mental do CCVP e tinham como proposta o suporte aos familiares dos usuários e aos próprios usuários que frequentam serviços de saúde mental e/ou apresentam transtornos mentais.

Para garantir a qualidade do atendimento à população e a continuidade do serviço, o CCVP conta com um protocolo para a realidade das VDs. Este protocolo, passado com antecedência e dialogado com os estudantes, consiste na realização de quatro etapas: (1) Planejamento, (2) Visita Domiciliar, (3) Supervisão e (4) Confecção do relatório. Esse roteiro garante a ideia de que a atividade não começa e nem termina com a visita em si.

\section{Resultados e discussão}

O planejamento em qualquer ação é imprescindível para o alcance do sucesso esperado, de forma a estabelecer os objetivos e construir o plano de execução. Em saúde, há planejamento em todos os níveis de trabalho, desde o planejamento do uso dos recursos municipais e distritais até a distribuição de programas e vacinas conforme o perfil epidemiológico da população, passando por planejamento de estruturais dos espaços e manejo de situações em equipes multidisciplinares. A falta de um planejamento adequado usualmente levará ao gasto desnecessário de recursos, baixo aproveitamento do tempo dos profissionais envolvidos, dificuldade em avaliar se a ação atingiu os objetivos previstos, entre outros desconfortos. (Silva et al., 2015).

Segundo Andrade et al. (2014), para que se faça uma boa visita domiciliar, o planejamento deverá ser bem estruturado. Portanto, antes de toda visita, eram dedicados tempo e concentração para realização do planejamento. No CCVP, tal etapa consistia em estabelecimento das famílias a serem visitadas, leitura do prontuário, preenchimento da ficha de planejamento e discussão entre a turma.

O estabelecimento das famílias a serem realizadas era feito pela supervisora com uma semana de antecedência ao dia da visita. A partir dos encaminhamentos realizados pela equipe de saúde e das famílias visitas anteriormente, a professora organizava quais casas seriam assistidas na semana seguinte. Com os dados em mãos, ela informava às agentes de saúde para que fizessem o agendamento das visitas com antecedência adequada.

No dia da VD nós estudantes realizávamos a leitura do prontuário, momento que era a primeira forma de contato com o sujeito em questão e a sua família. A partir do prontuário, era possível obter elementos e acontecimentos marcantes da história de vida dos usuários, dados clínicos e questões/ações que já foram trabalhadas. No prontuário constava instrumentos como Familiograma, Eco mapa e Diagrama das relações, que nos oferecia informações sobre vínculo e estrutura familiar, bem como, relacionamento dos usuários com os equipamentos sociais disponíveis, 
como templo religioso, casa de amigos ou familiares, trabalho, entre outros. O prontuário do CCVP é multiprofissional e por isso, podíamos acessar informações de outras categorias de saúde, o que muitas vezes, nos ofertava maior conhecimento sobre as pessoas, seus hábitos e cuidados. Todos os registros presentes no prontuário foram realizados pelos estudantes, residentes, professores-supervisores ou pela equipe de saúde em geral.

A principal função da leitura do prontuário é oferecer aos estudantes informações sobre a família e a sua situação de saúde, de modo a nos ajudar no estabelecimento de objetivos da visita em questão, além de nos preparar para as possíveis situações que poderíamos encontrar. Assim, as visitas seriam úteis e o trabalho realizado outrora por outros profissionais da Unidade de Saúde teriam continuidade. Até mesmo nos casos em que tínhamos pouca informação sobre o paciente no prontuário por se tratar de uma pessoa que pouco comparecia ao serviço ou era nova na área, o planejamento era realizado de modo a estabelecer objetivos de vinculação com o usuário e conhecer a sua história de saúde mental, bem como, outras questões sociais, familiares e emocionais que poderiam nos orientar em acompanhamentos futuros.

A partir das informações disponíveis, era realizado o preenchimento da ficha era uma espécie de condensação das informações mais importantes lidas no prontuário. A ficha, que é padronizada no CCVP para todas as VDs, consiste em preencher os itens: nome do sujeito que tinha transtorno mental, idade, objetivos da vida, principais problemas, condições de risco ou vulnerabilidade da família, principais estratégias de enfrentamento da família, e por fim, quais abordagens a serem utilizadas para atingir os objetivos. Usualmente os objetivos que elaboramos envolviam: orientações necessárias sobre a condição de saúde mental do sujeito e/ou sobre uso da medicação prescrita; a busca da resolução da lista de problemas e condições de risco ou vulnerabilidade; o fortalecimento das estratégias bem sucedidas encontradas pela família para lidar com as situações difíceis. Investia-se na criação de objetivos potentes e concisos que possibilitassem uma visita assistencial e educacional, tendo em vista a constante evolução do quadro do sujeito. Após a elaboração do planejamento, a discussão em grupo era realizada, visando decidir, coletivamente, se os objetivos e estratégias eram pertinentes.
A discussão em grupo era um momento de partilha em que avaliávamos com os colegas e a professora se os objetivos e as estratégias de abordagem estabelecidas estavam em consonância com a situação da família, sua lista de problemas e os relatos encontrados em prontuários. Havendo necessidade, fazíamos ajustes. Com o plano de trabalho em mãos, seguíamos para o momento da visita domiciliar.

Entretanto, como ilustram Romanholi e Cyrino (2012), por mais orientada que a visita domiciliar seja, não impossibilita a ocorrência de imprevistos. Apesar das visitas serem avisadas e confirmadas pelas agentes de saúde com antecedência, por vezes, saíamos do CCVP em direção ao domicilio e éramos surpreendidos pela ausência de pessoas na casa, bem como, a presença de elementos familiares que aconteciam para além do que estava planejado, o que necessitava de reorganização imediata do planejamento. $O$ fenômeno da surpresa, por si só, já nos exigia habilidade de um manejo clínico que não tínhamos vivido durante as aulas na faculdade, por exemplo.

Sobre a realização das visitas, a professora orientava que deveriam durar entre 20 e 30 minutos (tempo cronológico), porém, nos deparamos com mais de uma categoria de tempo no momento da visita: o tempo emocional, constatado por Sakata (et al., 2007) numa pesquisa com profissionais de saúde de uma Unidade Básica de Saúde (USB) em Ribeirão Preto. Esses profissionais, no momento da visita, lidavam com o tempo cronológico e o tempo emocional. O tempo cronológico diz respeito à duração das visitas e a conciliação do mesmo com o comprimento das tarefas e o tempo emocional envolve as relações e os vínculos construídos.

Na experiência do internato foi possível conhecer as duas perspectivas do tempo. O tempo cronológico é o que temos de concretude, surgindo, muitas vezes de forma desafiadora. Houve dias que os minutos passaram depressa e outros dias em que se arrastavam. Após analises dessas situações, foi possível concluir que a sensação de lentificação do tempo pôde ser atribuída, principalmente, a acontecimentos inesperados e desagradáveis da visita, a exemplo de: falta de colaboração do paciente para/com equipe de saúde (evitando responder as perguntas); discurso agressivo vindo de um dos membros da família, membro da família agindo de forma que julgamos ser prejudicial para a melhoria do sujeito adoecido, dentre outros. 
Já a sensação de aceleração do tempo dava um toque de brevidade na visita e acontecia em consequência à fluidez do encontro entre equipe, família e indivíduo. Essas visitas eram capazes de proporcionar satisfação profissional, uma vez que, na maioria das vezes, todos os objetivos eram cumpridos com eficácia e existia bastante cooperação da família. Para nós, internos de Psicologia, esses eram dias muito agradáveis.

O tempo emocional é muito especial, principalmente se encarado à longo prazo. Depois que a rotina de acompanhamentos de determinada família é estabelecida, percebe-se que os integrantes da família, em algum momento, passam a se sentir seguros diante da presença da equipe, depositando confiança nos mesmos e no trabalho que desenvolvem. Surge então a vinculação. A vinculação família-profissional é extremamente importante, já que, como Cunha e Sá (2013, p. 9) apontam "a VD implica certa exposição dos hábitos e rotinas privativas do usuário no espaço domiciliar. Assuntos particulares se tornam visíveis, alvo de avaliação dos profissionais de saúde e do seu saber-poder sanitário, legitimado pela ciência.". Deste modo, é importante que essas pessoas não se sintam expostas ou julgadas, e sim acolhidas e fortalecidas no vínculo que foi construído. Mandu, Gaíva, Silva e Silva (2008), valorizam as relações afetivas estreitas que os familiares estabelecem com os profissionais.

A vinculação era um assunto delicado para nós, pois passaríamos apenas 10 semanas no internato. Entretanto, percebemos que o vínculo das pessoas já era muito forte com o CCVP, então, agregamos ainda mais a esse vínculo, mantendo a qualidade do serviço, o olhar acolhedor, a escuta atenta e realizando orientações necessárias. A professora do internato também é um elo de continuidade do vínculo, por ser quem continua responsável pelo acompanhamento das famílias que visitamos, mesmo quando o rodízio se encerra.

No contexto das visitas domiciliares, adentrar o espaço alheio é defrontar-se com múltiplas realidades de vida. A maioria das famílias cadastradas no CCVP são pobres e as casas visitadas variavam de acomodações simples à precárias; contextos sociais que colocavam em risco o bem-estar daqueles que ali residiam. $\mathrm{O}$ primeiro momento com as famílias, também era o momento de conhecimento das suas instalações e, por vezes, tal momento era surpreendente, pois encontrávamos precariedades de quesitos básicos e estruturais, que inclusive poderiam ser considerados fatores de risco a saúde dos moradores. Borges \& D'Oliveira (2011) acreditam que ao conhecer a realidade de vida daquele usuário e família, torna-se possível compartilhar com eles os cuidados adequados a serem realizados. A ida ao domicílio é a melhor ferramenta para conhecer essa realidade.

Como aspecto desafiador, os cuidados que são prestados através das VDs são comumente interpretados como instrumentos de controle de saúde. Para França (et al., 2006), alguns profissionais atribuem a visita domiciliar o papel de controlar doenças e cobrar verdades sanitárias, o que pode ser bastante prejudicial para o relacionamento e vinculação, pois o processo torna-se inflexível e ignora saberes que não são científicos. $O$ atendimento domiciliar deve objetivar o trabalho de proteção à saúde, através de uma abordagem que seja educativa e que possibilite potencialidades individuais e coletivas para o melhor enfretamento de condições não favoráveis (Mandú et al., 2008). Durante os diálogos com a família tínhamos cautela para não sermos impositivos em relação às orientações dadas ou punitivos em relação aos hábitos que a família declarava.

Algo que também pode ser prejudicial e perigoso é a utilização em excesso das VDs, caso isso ocorra, elas passam a ser chamadas de "Visitas Domiciliares compulsórias". Pereira, Cézar, Silva, Reidorfer e Cardoso (2014), afirmam que tal tipo de visita, pode fazer com que os indivíduos enxerguem o setor de saúde como intrometidos e que colocam sua liberdade em risco. Todos esses aspectos eram cuidadosamente pensados juntamente com a professora e os colegas antes da realização das visitas, pois, como estudantes de Psicologia, não devemos cair no papel de um agente controlador e fiscalizador, que dita ordens e regras. Incluímos aqui a ressalva que tal reflexão deve-se ao carácter da VD que realizamos, que visa a orientação, acolhimento, escuta e realização de possíveis encaminhamentos aos usuários de saúde mental e suas famílias. Para o sucesso das nossas VDs é fundamental que as pessoas estejam confortáveis e desejem nos receber. Já as VDs que se caracterizam pelo nível da atenção secundária ou terciária e com isso visam o atendimento aos usuários que muitas vezes são dependentes de serviços de saúde, como, dependentes de respiradores, feridos, em cuidados paliativos, entre outros, em diversos casos necessitarão serem realizadas mais de uma vez por semana. 
Por sermos psicólogas em formação, as visitas destinadas a nós, no CCVP, eram aquelas com foco e atenção em Saúde Mental. Por isso, todas as famílias selecionadas para realização das visitas possuíam um ou mais de um, dos seus membros com algum tipo de transtorno mental. Assim sendo, toda ação do trabalho era focada no indivíduo e na sua família, já que, pensando na desinstitucionalização do cuidar, a família é a principal responsável no manejo dos cuidados do sujeito. As VDs configuram-se como instrumentos facilitadores na abordagem do paciente com transtorno mental e sua família, pois permite o acompanhamento de forma individual mergulhado na realidade própria daquele núcleo, entendo a sua dinâmica, oferecendo suporte no cuidado, tratamento, reinternação, etc (Pereira et al., 2014).

Nesse sentido, as VDs com foco em saúde mental são uma técnica muito eficaz como ação da Reforma Psiquiátrica. Isso pode ser afirmado, pois a ressocialização do usuário perpassa pela compreensão da sua realidade e pela busca dos recursos e equipamentos que cada pessoa dispõe. A equipe de saúde tem como função fazer essa averiguação e oferecer ao usuário as possibilidades encontradas. Na nossa experiência, nós tivemos a oportunidade de oferecer às pessoas que visitamos as informações sobre os grupos existentes no CCVP, sobre os cursos gratuitos que o CCVP tem em parceria com o SENAI/BA e estimular a ida às atividades do Centro de Atenção Psicossocial, localizado em Vale dos Lagos.

Um outro ponto importante é o conceito de família como um sistema orgânico. O que implica dizer que quando uma pessoa do sistema adoece, todos adoecem juntos, principalmente quando a doença envolve um forte sofrimento psíquico. É exigido da família uma reorganização para o cuidado, de modo a não sobrecarregar apenas um cuidador, mas quando possível, dividir as tarefas necessárias com todos os membros do sistema. A VD é uma necessidade de toda a família, porque muitas vezes os familiares precisam de orientação para o melhor cuidar e de acolhimento emocional. (Schrank \& Olschowsky, 2008)

Com esses aspectos em foco, sempre que possível prezávamos pelo atendimento em conjunto com os membros presentes no momento na casa. Pudemos vivenciar desde momentos muito interessantes de partilha e apoio mútuo entre os familiares até situações de brigas e conflitos. Esses momentos, apesar de nos causar desconforto e insegurança como estudantes, eram considerados por nós como a chance que as pessoas tinham de expor suas dificuldades e frustrações. Como já tínhamos feito o estudo do prontuário, as informações sobre o relacionamento dos familiares estava. Eram oportunidades que tínhamos de intervir no funcionamento familiar, orientando para uma busca de funcionalidade e realização de novos acordos entre os membros, através de uma reflexão do papel de cada um no contexto em debate. Como afirmado por Pietroluongo e Resende (2007), é função da psicóloga facilitar a comunicação entre as pessoas, por meio das habilidades de dialogar e escutar. Como estudantes de psicologia, foi muito rico viver esses momentos e adquirir tais habilidades.

O internato é uma oportunidade ímpar para adquirir competências que tornam a análise da realidade do sujeito crítica; o que facilitará uma construção de intervenções coerente com determinado contexto sociocultural (Santos e Nóbrega, 2017).

Após o retorno da visita, os estudantes reuniam-se com a professora para o momento da supervisão. Em Psicologia, a supervisão é um momento que simboliza a passagem dos aprendizados teóricos para uma aprendizagem prática, que inclui o desenvolvimento de novas competências. Esse momento formativo articula e facilita a transição da teoria para prática, sendo assim, de importância vital para o estudante de psicologia progressivamente tornar-se psicólogo. (Silva et al., 2020)

Para nós, a supervisão era um momento estrutural no desenvolvimento da nossa criticidade. Naqueles momentos podíamos avaliar nosso amadurecimento enquanto agentes de saúde e elencar pontos de meIhoria para as próximas visitas. Aprende-se a realizar as visitas indo até os domicílios, mas também, certamente, usufruindo de um espaço onde é permitido a exposição de dúvidas e limitações, escuta de experiências dos colegas, troca de conhecimentos a respeito de tópicos específicos e principalmente, orientação da professora, que oferece conhecimento e segurança.

O ganho de experiência obtido em momentos de supervisão, são fundamentais para a formação e tal momento deve ser compreendido como momento de facilitação e de suporte para os estudantes (Pitombeira et al., 2016). Portanto, nota-se a necessidade da supervisão como requisito para a atividade de visitação domiciliar. Além de servir como fortaleza para nós, com a condução de uma professora - psicóloga, a 
supervisão passa a ser a ocasião responsável por propiciar discussões embasadas teoricamente a respeito da prática realizada. A supervisão é um espaço fértil para discussão teórica que favorece articulação com a prática associada às condições de trabalho (Santos e Nóbrega, 2017).

Além desse fator, a supervisão era um momento de avaliação entre os objetivos desenvolvidos no planejamento e os objetivos alcançados. Em alguns casos, não conseguíamos cumprir os objetivos por falta de tempo, falta de manejo ou intercorrências diversas. Quando o motivo era falta de manejo, precisávamos encontrar junto com os colegas e a professora o ponto em que não soubemos conduzir e reavaliar as possibilidades futuras. A depender da situação, a professora assumia uma postura desafiadora ou acoIhedora, pois conforme nos dizem Morgado e colaborares (et al., 2018), as funções do supervisor incluem informar, questionar, sugerir, encorajar e avaliar.

Entretanto, quaisquer dessas intervenções necessitam de um clima afetivo para que o desenvolvimento e aprendizagem dos estudantes seja efetivo. $\mathrm{O}$ supervisor precisa apresentar uma boa habilidade de escuta, capacidade cooperativa, facilidade de comunicação, encorajamento e entusiasmo pela profissão, entre outros, (Morgado et al., 2018), elementos que pudemos encontrar nessa experiência desenvolvida.

Levando em consideração a possibilidade de deparar-se com o imprevisto que as VDs impõem, Duarte (2015) complementa que "supervisão enquanto dispositivo é pensar as possibilidades para enfrentar as impossibilidades" (p. 6). Na nossa experiência, a supervisão era, em geral, um espaço poderoso e encorajador de todo o trabalho realizado; sempre ancorados em teorias psicológicas. Foi vantajoso e pertinente falar dos casos atendidos e ouvir os casos dos colegas, aproveitando todas as discussões para uma melhor e ativa construção das psicólogas que queremos ser.

Por fim, era realizada a confecção do relatório da visita. Andrade (et al., 2013) atribuem importância a essa etapa, pois acreditam através de tal registro é possível obter informações sobre o usuário visitado e sua família e realizar análise periódica do seu estado de saúde, além de servir como ferramenta de avaliação das VDs.
Para Machado (2014), registrar semanalmente as atividades práticas é uma forma de não acontecer aprisionamentos nas sensações e opiniões. Registrar semanalmente é um exercício constante de aperfeiçoamento da técnica. O primeiro relatório feito em campo foi acompanhado de questionamentos sobre o que escrever, quais seriam as palavras mais adequadas e sobre a natureza do relato - se baseado em impressões pessoais ou não. A professora dedicou-se a retirada de dúvidas e de orientações que são fundamentadas em princípios éticos e no Código de Ética do Psicólogo.

Machado (2014) afirma que uma escrita com um caráter de julgamento muito marcante, é capaz de definir toda uma vida por um estado. Ou seja, escrever deixando vieses, pode ser responsável pela generalização da totalidade de um indivíduo a um só termo ou adjetivo que seja empregado de forma muito contundente. A autora ainda acrescenta que "a escolha de palavras e frases que tragam a multiplicidade presente em uma situação exige tempo" (Machado, 2014, p. 9).

No início do rodízio, passávamos muito tempo para produzir um relatório que julgássemos como 'ideal'. Eram necessárias muitas folhas de rascunho, auxílio constante da professora e muitas pesquisas nos relatórios que estavam disponíveis no prontuário da família. Conforme o tempo foi passando, fomos criando segurança no processo e construindo um modelo mental do que era necessário ser registrado; aqui, já sabíamos quais palavras utilizar na confecção de um instrumento que servirá de base para visita dos próximos internos e quais informações da visita deveriam ser suprimidas, afim de resguardar o sigilo do paciente e sua família.

Quando precisávamos de suporte, porque não nos sentíamos seguros o suficiente pra escrever o nosso relatório do zero, tínhamos o apoio de algumas dezenas de relatórios disponíveis e é muito significativo pensar que no futuro, serão os nossos relatórios que serão lidos, estudados e consultados por outros estudantes e profissionais. Através deles, novas pessoas se comoverão com as histórias lidas e embasarão suas visitas e atendimentos. Por isso, era preciso, além de tudo, ter compromisso e zelo com o que escolhíamos registrar. Sabíamos que o mais importante de tudo, era que o trabalho que estava sendo realizado, deveria ser realizado eticamente. Almejando que os próximos profissionais, deem seguimento a esses preceitos. 


\section{Considerações finais}

Desde 2006, a Estratégia de Saúde da Família (ESF) passou a idealizar um modelo de atenção básica à saúde que se contrapusesse ao estilo baseado na lógica curativa e medicalizante que regia aquele momento. Dessa forma, as Visitas Domiciliares são pensadas para a atenção à família e ao território; trabalhando com ações de prevenção de doenças e promoção e assistência à saúde. Desde então, as VDs são encaradas como instrumento central no processo de trabalho das equipes de saúde da família.

Ademais, se trabalhadas em contextos acadêmicos, as VDs são potentes instrumentos de formação. Os estudantes que vivem essa atividade em serviços públicos de saúde saem carregados de experiências enriquecedoras e principalmente, com visão ampliada sobre a vida e as relações humanas. Ter a possibilidade de constante deslocamento e descobertas é o que torna a experiência do internato, inesquecível. A VD permite ao aluno desenvolver habilidades de comunicação e observação, construir vínculos com outras pessoas, a aproximação da realidade e do cotidiano daquelas famílias e a compreensão sobre as condições de saúde da população brasileira.

Por se tratar de um meio de atenção que envolve muita proximidade entre contextos de vida, equipe e famílias, é possível que tais profissionais se encontrem pessoalmente envolvidos com determinado caso, o que pode gerar sentimento de frustração e impotência diante de determinadas situações. Com o vínculo muito intenso, pode ser que a família se sinta abandonada caso o profissional mude de emprego ou não compareça ao domicílio durante um período por motivos diversos como, adoecimento, férias, períodos de chuvas fortes que impeçam a visita ou tensionamento entre grupos de tráfico e/ou policiais que coloquem em risco a vida da equipe de saúde. Nesses casos, faz-se necessário que a família seja bem informada sobre o motivo que levou a suspensão temporária das visitas; esse contato pode ser feito através de telefone. Além desse aspecto, a presença da faculdade em serviços de saúde pode ser um componente negativo para comunidade se os alunos são/estão descomprometidos e desinteressados com o serviço. Acreditamos ser essa a principal limitação das VDs como atividade docente-assistencial. É possível que apenas um estudante descomprometido prejudique toda uma trajetória de trabalho realizada ao longo dos anos com a família.
Contudo, existe um grande ponto positivo para os universitários de Psicologia que realizam as visitas dentro do contexto de atividades curriculares, esse ponto diz respeito à atuação na atenção primária a saúde. Na graduação em Psicologia, é predominante o interesse pela área clínica, no seu modelo tradicional de atendimento, dessa forma, outros espaços de atuação são, por vezes, desvalorizados. Por isso, se tratando de um momento de formação, torna-se necessário que o aluno tenha contato com outras possibilidades de profissionalização, atividades diferentes daquela que já está estabelecida como primeira opção. Independente das escolhas que serão feitas no futuro, adquirir o "saber fazer" dentro de determinada área é algo que agrega conhecimento e experiência para a jornada profissional. A partir das práticas durante a graduação, como o internato, é possível aprender novas formas de relacionamento, estratégias para resolução de problemas e elementos para a compreensão do que é ser psicólogo.

O internato foi responsável pela nossa inserção como estudante no mundo do trabalho. Em relação à vivência no CCVP, nunca havia experimentado uma relação com claro cunho terapêutico no contato com o outo. Viver a experiência com autonomia para guiar os planejamentos e as condutas, mas ao mesmo tempo, tendo sempre a orientação e o apoio da professora foi o grande diferencial. Finalmente, é muito significativo e pertinente que a estudante aprenda sobre o que é ser psicóloga dentro de um contexto assistencial-pedagógico, pois assim poderá materializar as competências e habilidades requeridas para o exercício efetivo da profissão.

\section{Contribuições das autoras}

Araújo CMR e Silva JP foram responsáveis por todas as etapas para construção do artigo: concepção, delineamento, análise e interpretação dos resultados, redação, revisão e aprovação final.

\section{Conflitos de interesses}

Nenhum conflito financeiro, legal ou político envolvendo terceiros (governo, empresas e fundações privadas, etc.) foi declarado para nenhum aspecto do trabalho submetido (incluindo, mas não se limitando a subvenções e financiamentos, participação em conselho consultivo, desenho de estudo, preparação de manuscrito, análise estatística, etc.). 


\section{Referências}

Andrade, A. M., Guimarães, A. M. D. N., Costa, D. M., Machado, L. C., \& Gois, C. F. L. (2014). Visita domiciliar: Validação de um instrumento para registro e acompanhamento dos indivíduos e das famílias. Epidemiologia e Serviços de Saúde, 23(1), 165-175. https://doi.org/10.5123/S167949742014000100016

Berlinck, M. T., Magtaz, A. C., \& Teixeira, M. (2008). A Reforma Psiquiátrica Brasileira: Perspectivas e problemas. Revista Latinoamericana de Psicopatologia Fundamental, 11(1), 21 28. https://doi.org/10.1590/S1415-47142008000100003

Borges, R., \& D'Oliveira, A. F. P. L. (2011). A visita médica domiciliar como espaço para interação e comunicação em Florianópolis, SC. Interface comun. saúde educ, 461-472. http://www.scielo.br/scielo.php?script=sci_ arttext\&pid=S1414-32832011000200011

Cunha, M. S., \& Sá, M. C. (2013). Home visits within the family health strategy (estratégia de saúde da familia - ESF): The challenges of moving into the territory. Interface Comunicação, Saúde, Educação, 17(44), 6173. https://doi. org/10.1590/S1414-32832013000100006

Duarte, D. A. (2015). A supervisão enquanto dispositivo: Narrativa docente do estágio profissional em psicologia do trabalho. Interface - Comunicação, Saúde, Educação, 19(52), 133-144. https://doi.org/10.1590/1807-57622014.0170

França, S. P., Pessoto, U. C., \& Gomes, J. O. (2006). Capacitação no Programa de Saúde da Família: Divergências sobre o conceito de visita domiciliar nas equipes de Presidente Epitácio, São Paulo. Trabalho, Educação e Saúde, 4(1), 93108. https://doi.org/10.1590/S1981-77462006000100006

Gama, C. A. P., \& Koda, M. Y. (2008). Psicologia comunitária e programa de saúde da família: Relato de uma experiência de estágio. Psicologia: ciência e profissão, 28(2), 418-429. https://doi.org/10.1590/S1414-98932008000200015

Gibertoni, J. (1967). A importância do planejamento do centro cirúrgico. Revista da Escola de Enfermagem da USP, 1(1), 7987. https://doi.org/10.1590/0080-6234196700100100079

Machado, A. M. (2014). Exercer a Postura Crítica: Desafios no Estágio em Psicologia Escolar. Psicologia: Ciência e Profissão, 34(3), 761-773. https://doi.org/10.1590/19823703001112013
Silva, C. M. C., Teixeira, E. R., Sabóia, V. M., \& Valente, G. S. C. (2011). visita domiciliaria en la atención a salud mental. Ciencia y Enfermería, 17(3), 125-136. https://doi. org/10.4067/S0717-95532011000300011

Mandú, E. N. T., Gaíva, M. A. M., Silva, M. A., \& Silva, A. M. N. (2008). Visita domiciliária sob o olhar de usuários do programa saúde da família. Texto \&Contexto - Enfermagem, 17(1), 131-140. https://doi.org/10.1590/S0104$\underline{07072008000100015}$

Morgado, E. M. G., Silva, L. L. F., Rodrigues, J. B., Morgado, E. M. G., Silva, L. L. F. da, \& Rodrigues, J. B. (2018). The universe of supervision: An inclusive approach in the field of professional integration. Pro-Posições, 29(3), 492-516. https://doi.org/10.1590/1980-6248-2016-0048

Parecer CNE/CES n ${ }^{\circ}$ 1071/2019, de 4 de dezembro de 2019. Revisão das Diretrizes Curriculares Nacionais (DCNs) dos Cursos de Graduação em Psicologia e estabelecimento de normas para o Projeto Pedagógico Complementar (PPC) para a Formação de Professores de Psicologia. http://portal.mec. gov.br/index.php?option=com_docman\&view=download \&alias=139201-pces1071-19\&category_slug=dezembro2019-pdf\&Itemid=30192

Pereira, S. S., Cézar, J. G. S., Reisdorfer, E., \& Cardoso, L. (2014). Visita domiciliar aos pacientes portadores de transtorno mental: Ampliando as opções terapêuticas possíveis em um serviço ambulatorial. Saúde \& Transformação Social, 5(1), 91-95. http://pepsic.bvsalud.org/scielo.php?script=sci_ abstract\&pid=S2178-70852014000100014\&Ing=pt\&nrm=i so\&tlng=pt

Pietroluongo, A. P. C., \& Resende, T. I. M. (2007). Visita domiciliar em saúde mental: O papel do psicólogo em questão. Psicologia: ciência e profissão, 27(1), 22-31. http://pepsic. bvsalud.org/scielo.php?script=sci_abstract\&pid=S141498932007000100003\&Ing=pt\&nrm=iso\&tlng=pt

Pitombeira, D. F., Xavier, A. S., Barroso, R. E. C., \& Oliveira, P. R. S. (2016). Psicologia e a Formação para a Saúde: Experiências Formativas e Transformações Curriculares em Debate. Psicologia: Ciência e Profissão, 36(2), 280-291. https://doi. org/10.1590/1982-3703001722014

Portaria n. 336 de 19 de fevereiro de 2002. Estabelece que os Centros de Atenção Psicossocial poderão constituir-se nas seguintes modalidades de serviços: CAPS I, CAPS II e CAPS III, definidos por ordem crescente de porte/complexidade e abrangência populacional. http:// http://bvsms.saude. gov.br/bvs/saudelegis/gm/2002/prt0336_19_02_2002.html 
Portaria n. 3.088, de 23 de dezembro de 2011. Institui a Rede de Atenção Psicossocial para pessoas com sofrimento ou transtorno mental e com necessidades decorrentes do uso de crack, álcool e outras drogas, no âmbito do Sistema Único de Saúde (SUS). http://bvsms.saude.gov.br/ bvs/saudelegis/gm/2011/prt3088_23_12_2011_rep.html

Romanholi, R. M. Z., \& Cyrino, E. G. (2012). Home visits in doctors' training: From conception to the challenge of practice. Interface - Comunicação, Saúde, Educação, 16(42), 693-705. https://doi.org/10.1590/S1414-32832012000300009

Sakata, K. N., Almeida, M. C. P., Alvarenga, A. M., Craco, P. F., \& Pereira, M. J. B. (2007). Conceptions of the family health team about home visits. Revista Brasileira de Enfermagem, 60(6), 659-664. https://doi.org/10.1590/5003471672007000600008
Santos, A. C., \& Nóbrega, D. O. (2017). Dores e Delícias em ser Estagiária: O Estágio na Formação em Psicologia. Psicologia: Ciência e Profissão, 37(2), 515-528. https://doi. org/10.1590/1982-3703002992015

Schrank, G., \& Olschowsky, A. (2008). O centro de Atenção Psicossocial e as estratégias para inserção da família. Revista da Escola de Enfermagem da USP, 42(1), 127134. https://doi.org/10.1590/S0080-62342008000100017

Silva, B. F. S., Wandekoken, K. D., Dalbello-Araujo, M., \& Benito, G. A. V. (2015). The relevance of planning as management practice in health micro region of São Mateus (ES). Saúde em Debate, 39(104), 183-196. https://doi.org/10.1590/0103110420151040078

Silva, N. O., Pinheiro, M. A., \& Laurendon, C. E., (2020). Construction of meanings and ambiguities in the context of internship supervision in psychology. Psicologia USP, 31, e200064. https://doi.org/10.1590/0103-6564e200064 